\title{
EDITORIAL
}

\section{Retention of Anatomy Knowledge}

Anatomy teachers in medical faculties are often held responsible by clinicians especially surgeons for the inability of undergraduates to answer questions related to anatomy, once they start clinical training, having passed anatomy as a preclinical subject. This is a universal problem and anatomy teachers world over are faced with the challenge to overcome this issue. Having introduced more clinically oriented methods of teaching anatomy and including more clinically oriented questions at main examinations, the problem still remains.

Any subject, once learned, will not be retained indefinitely in one's mind without repeated re-exposure. Anatomy is no exception, and it would be interesting to see how knowledge in anatomy has been retained in those actively involved in the field of medicine for many years.

The Department of Anatomy at the Faculty of Medicine, Peradeniya embarked on a study few years back in collaboration with the Griffith School of Medicine, Australia to explore this issue. The preliminary results showed that the ability to recall basic anatomy is significantly affected by the length of time after passing anatomy as a subject. Medical students, few months after their main anatomy examination, as expected, retained better than final year students. Whereas consultants having completed their postgraduate examinations, in which basic anatomy is one important component, were much worse than the final year medical students and intern house officers who are getting trained under their own supervision. This finding could be an eye opener for those who plan to improve retention of anatomy knowledge in students where new strategies need to be introduced to overcome the issue.

A feasible solution that is being currently tested under the aforementioned research project is to introduce an online module that can be used by doctors and students as an inservice revision of their knowledge. The said module is being designed in such a way that based on the sub-field of medicine concerned, the user could revise the knowledge relevant to the field as the need arises. For instance, a medical officer transferred to a psychiatry unit after serving in the outpatient department for several years may revise the section on brain whereas a medical officer who is about to commence in the orthopedic unit will study the section on the skeleton and limbs. Once introduced, the medical students will be instructed to revisit the module from time to time based on their on-going field of training. In 
parallel the extended clinical staff will be requested to reiterate the students whom they think have forgotten the basic facts to make use of the online module.

There is no question that it is our duty as anatomy teachers to be open-mined to criticism about our teaching and improve its quality and relevance, but at the same time it is not fair by the subject of Anatomy, which is one of the main pillars on which the field of medicine stands, to allow irrational and prejudiced attacks upon it.

Professor SanjayaAdikari $(M B B S, P h D)$

President of the Anatomical Society of Sri Lanka

Professor of Anatomy 